\title{
Welcome to the inaugural issue of the EJPE
}

According to John Stuart Mill, "the definition of a science has almost invariably not preceded, but followed, the creation of the science itself" (Mill 1844, 86). The subject matter, the methods, the main topics and questions, the foremost goals and challenges, all such elements need to be properly understood before a suitable definition of the discipline can be established. Mill was referring to economics. Yet, today there is still no full agreement on what exactly economics is, what it is supposed to be about, nor on the methods that it should employ.

Since the early nineteenth century, such reflections on the nature of economics-its definition, subject matter, methodology, logic, epistemic and empirical basis, normative implications, as well as its relations to other fields-have slowly given rise to the new field of philosophy of economics. However, this development has been rather sporadic, possibly due to the disciplinary structures and boundaries that have, for example, limited enthusiasm for economic methodology among philosophers of science, and isolated historians of economic thought from their colleagues in economics departments interested in the relevance of the past for a better understanding of contemporary economic theory. Indeed, significant full-fledged attempts to organise, systematise, and recognise philosophy of economics as a distinct discipline only started some 30 years ago. ${ }^{1}$

Nonetheless in recent decades various international institutions and academic journals have begun to appear, including the International Network of Economic Method (INEM) with its specialised and highly regarded Journal of Economic Methodology and the prestigious and more general Economics and Philosophy. ${ }^{2}$ These organisations have mainly served to shape and develop the exchange of ideas among people who were already knowledgeable and active in the philosophy of economics, thus bringing about a mostly highly specialised academic exchange.

\footnotetext{
Some representative examples of this stage are Rosenberg 1976; Blaug 1980; Hausman 1981; Caldwell 1982; Boland 1982, 1989; McCloskey 1985; Dow 1985; Hoover 1988; Mirowski 1988. For more recent overviews see Backhouse 1994; Hands 2001; and Hausman 2008.

${ }^{2}$ Many more philosophy and economics resources can be found in the 'Related Links' section of the EJPE Website: <http://ejpe.org/related-links/>
} 
This stage was followed in 1997 by the founding of the successful Erasmus Institute for Philosophy and Economics (EIPE) by a small international group of academics. At the time, EIPE was the only graduate institute entirely devoted to the training and research in the philosophy of economics. Since then, EIPE has played a significant role in the increasingly integrated state of the philosophy of economics.

In spite of lacking a precise definition for economics, it seems fair to say that almost everybody has at least an informal idea of what economics is all about: people in general have some notion about what economists might actually be doing. Things are entirely different for the philosophy of economics. As graduate students in the field, one of our aims with starting this new Erasmus Journal for Philosophy and Economics is to change all that. We want to spread the recognition and influence of the topics and the research being carried out in the philosophy of economics, and to persuade more academics from different disciplines to read and publish on crucial topics in the field.

The overall purpose of EJPE is therefore to provide a forum for the growing scholarly research that lies at the intersection of philosophy and economics. This intersection includes not only the philosophy of science applied to the special case of economics, but also research in the history of economic analysis which contributes to a better understanding of the contexts, ideologies, and culture behind the development of economic theory. Similarly, we want to include conceptual reflections on inter-disciplinary relations between economics and other disciplines, which have the capacity to enrich our understanding of all fields involved. EJPE's emphasis lies on publishing outstanding and original research, while also supporting the expansion and integration of the field by publishing critical survey papers by well regarded experts.

As a graduate student-run journal we recognise that EJPE has to demonstrate its academic credentials from the very beginning. Among our top priorities is depth in content (important, original, and rigorous research) supported by a formal and authoritative peer-review process. On this note, we are delighted that so many well-established academics have given generously of their time and expertise to assist in the selection and shaping of our submissions, and we have been no less impressed by the commitment and thoroughness of our young scholar referees. 
In the same vein, we would like to stress some distinguishing features that we believe set EJPE apart from many other academic journals in a significant way. EJPE is particularly committed to supporting and encouraging young scholars (both graduate students and recent PhDs). This objective is built into the very structure of EJPE in a number of ways, including content, style, and participation. The breadth of our content is meant to be particularly relevant for young scholars who have not yet specialised in their research efforts and who may have bold inter-disciplinary perspectives. EJPE also contains a special section in which recent $\mathrm{PhDs}$ can publish short summaries of their theses in order to introduce their work to a wide and diverse audience, and to promote interaction among researchers working on related topics.

We have tried to give EJPE an open and supportive style that young scholar contributors will find particularly welcoming, for example, in designing our submission and peer-review processes so as to emphasise timely and constructive feedback to authors at every stage. We are committed to maintaining an efficient peer-review system that provides authors with initial decisions within 2 to 3 months, and this means that our publishing cycle is much faster than the norm. In addition, the journal encourages young scholars with relevant expertise to gain experience within the academic world by participating first-hand as referees and book reviewers. We are also proud that all EJPE issues will be free to access online, as a young-scholar friendly resource to everybody interested in the subject.

EJPE will also contribute by informing and raising critical debate among circles that are not yet so acquainted with philosophical discussions about economics. We hope thereby to support the development of interdisciplinary relations and conversations, not only directly between philosophers and economists, but also among a broader range of young practitioners and theorists from all existing schools of economics, the humanities, and social sciences.

EJPE also makes a concerted effort to follow important ongoing debates in philosophy and economics by commissioning expert articles and book reviews. In this issue, for instance, we took a closer look at the debate over Stephen Ziliak and Deirdre McCloskey's controversial work on statistical significance by inviting a book-review from Aris Spanos, and a reply to Spanos's review from Ziliak and McCloskey. 
The initial response to our project has been impressive and encouraging. We are delighted to have received a large number of submissions for this inaugural issue from both well-established academics and young scholars all around the world, confirming that there is a great deal of interest in what this journal is meant to offer. In addition to several book reviews and $\mathrm{PhD}$ thesis summaries, this inaugural issue of EJPE contains five articles and one interview.

Opening the issue, Alessandro Lanteri examines the charge that students of economics are more selfish than students of other disciplines, as has been suggested by various economic experiments. Lanteri then explores in detail the alternative suggestion that economists are naturally selfish before their training begins and hence 'self-select' into studying economics. According to Lanteri, the selfselection explanation has been so readily accepted by economists because it requires no real self-examination of their teaching methods and contents; thus little effort has been made to properly corroborate it, while the roles of other plausible mechanisms, such as 'framing', have been neglected.

Next, Maurice Lagueux draws on the recent work of philosophereconomist Don Ross on microexplanation, and questions whether or not such work is contributing to a revolution in the methodology of economics by challenging the central pillars of the discipline: methodological individualism and the concept of rationality. More than an inquiry into the revolutionary status of economic methodology, however, Lagueux provides an in depth overview and analysis of the philosophical ideas that Ross has introduced to the economics literature, including Daniel Dennett's 'intentional stance'. Following Lagueux's article, in a short response, Don Ross himself elaborates on his points of contention with Lagueux's analysis and conclusions.

Following the pioneering work of Wade Hands and others, David Tyfield inquires into the potential for establishing an economics of scientific knowledge (ESK) from the sociology of scientific knowledge (SSK) literature. While acknowledging SSK's well-known problem of reflexivity, Tyfield argues that there are other, and more serious, philosophical problems with SSK that need to be rectified prior to developing an SSK-based ESK, requiring the introduction of a 'critical philosophy'.

In 'Bernard Mandeville and the 'economy' of the Dutch' Alexander Bick explores Mandeville's thoughts as elucidated in 'Remark Q' of The 
Fable of the Bees. While historians of economics have traditionally focused on those elements of Mandeville's thought that figured prominently in the development of Adam Smith's thinking, Bick's paper sheds new light on how the development of political economy was informed by close examinations of actual economic practice: Bick explores Mandeville's first-hand account of England's economic possibilities in relation to the commercial experiences of the Dutch.

Cristina Marcuzzo's article is an invited adaptation of her presidential address to the 2007 annual conference of the European Society for the History of Economic Thought (ESHET), in which she considers the past, present, and future of the history of economic thought (HET). She describes a typology of four different techniques of HET and evaluates the roles they have played in the discipline; she also rejects the split between the good economist and the good historian, in relation to the required skills for a suitable HET. The demands of the subject require good historians of economics to be well-versed in both disciplines and able to toggle between deep context and (contemporary) economic theoretical frameworks.

As a special contribution to this inaugural issue of EJPE, we present the first of an envisaged series of interviews with well-established philosophers and economists. Uskali Mäki has been among the most important proponents, researchers, and institution builders of the discipline of philosophy of economics ever since its emergence three decades ago. Today he continues to contribute new and interesting projects to the field. In this interview, he offers his opinions on the current state of the philosophy and methodology of economics, a firsthand overview of the development of his own thought, as well as some detailed clarifications of his current philosophical ideas.

As we have quickly learned, editing an academic journal involves a variety of challenges and rewards. There is the challenge of juggling opposing interests pulling in quite different directions: to publish high quality original research, while simultaneously ensuring a diversity of contributions across the journal's domains; to steer a reasonable path between opposing but well-argued referee reports; and so on. The first time an editor has to read a submission and decide whether it is a candidate for publication, they quickly realise the weight of the responsibility. But these real challenges are coupled with many rewards, from learning how certain aspects of academia work "behind the scenes" and developing valuable relationships with colleagues, to the 
sense of achievement derived from guiding a submission all the way through the peer-review process into a published issue of EJPE. We hope that we, as editors, have lived up to the expectations and responsibilities entrusted to us by our colleagues and friends in the academic community.

We are grateful to the Department of Philosophy at Erasmus University Rotterdam for generous funding, and to the many members and friends of EIPE who have provided advice and support. And in addition to the authors who made this issue possible, we would like to extend our thanks to the referees and the EJPE Advisory and Executive Boards for helping to transform EJPE from a lofty idea to a reality. We hope you all enjoy the outcome.

TYLER DESROCHES

LUIS MIRELES-FLORES

THOMAS WELLS

The EJPE Editors

<editors@ejpe.org>

\section{REFERENCES}

Backhouse, Roger E. (ed.). 1994. New directions in economic methodology. London: Routledge.

Blaug, Mark. 1980. The methodology of economics: or how economists explain. Cambridge: Cambridge University Press.

Boland, Lawrence A. 1982. The foundations of economic method. London: Allen \& Unwin.

Boland, Lawrence A. 1989. The methodology of economic model building: methodology after Samuelson. London: Routledge.

Caldwell, Bruce J. 1982. Beyond positivism: economic methodology in the twentieth century. London: Allen \& Unwin.

Dow, Sheila C. 1985. Macroeconomic thought: a methodological approach. Oxford: Basil Blackwell.

Hands, D. Wade. 2001. Reflection without rules: economic methodology and contemporary science theory. Cambridge: Cambridge University Press.

Hausman, Daniel M. 1981. Capital, profits, and prices: an essay in the philosophy of economics. New York: Columbia University Press.

Hausman, Daniel M. 2008. Philosophy of Economics. The Stanford Encyclopedia of Philosophy (Fall 2008 Edition), ed. Edward N. Zalta. SEP Website.

http://plato.stanford.edu/archives/fall2008/entries/economics/ (accessed November 2008). 
Hoover, Kevin D. 1988. The new classical macroeconomics: a sceptical inquiry. Oxford: Basil Blackwell.

McCloskey, D. N. 1985. The rhetoric of economics. Madison: University of Wisconsin Press.

Mill, John Stuart. 1844 [1836]. On the definition of political economy, and on the method of investigation proper to it. In Essays on some unsettled questions of political economy, J. S. Mill. London: Batoche Books, 86-114.

Mirowski, Philip. 1988. Against mechanism: protecting economics from science. Totowa (NJ): Rowman \& Littlefield Publishers.

Rosenberg, Alexander. 1976. Microeconomic laws: a philosophical analysis. Pittsburgh: University of Pittsburgh Press. 